\title{
MicroRNA-486-5p enhances hepatocellular carcinoma tumor suppression through repression of IGF-1R and its downstream mTOR, STAT3 and c-Myc
}

\author{
RANA AHMED YOUNESS ${ }^{1}$, HEND MOHAMED EL-TAYEBI ${ }^{2}$, REEM AMR ASSAL $^{2}$, \\ KARIM HOSNY ${ }^{3}$, GAMAL ESMAT ${ }^{4}$ and AHMED IHAB ABDELAZIZ ${ }^{2}$
}

\begin{abstract}
Departments of ${ }^{1}$ Pharmaceutical Biology and ${ }^{2}$ Pharmacology and Toxicology, Faculty of Pharmacy and Biotechnology, German University in Cairo, New Cairo City, Cairo $11835 ;{ }^{3}$ Department of General Surgery, Faculty of Medicine, Cairo University; ${ }^{4}$ Department of Endemic Medicine and Hepatology, Cairo University, Giza 12613, Egypt
\end{abstract}

Received August 3, 2015; Accepted June 16, 2016

DOI: $10.3892 / 01.2016 .4914$

\begin{abstract}
The insulin-like growth factor (IGF)-axis has been paradigmatically involved in hepatocellular carcinoma (HCC) tumor initiation, progression and drug resistance. Consequently, members of the IGF-axis and most importantly, IGF-1 receptor (IGF-1R) have been considered as intriguing targets for HCC therapy. Few miRNAs have been recently reported to be associated with IGF-1R regulation. The present study aimed to investigate the role of microRNA (miRNA/miR)-486-5p in the regulation of IGF-1R and its downstream signaling cascades. miR-486-5p was markedly downregulated in hepatitis $\mathrm{C}$ virus-induced HCC tissues and Huh-7 cells. Forcing the expression of miR-486-5p in Huh-7 cells resulted in the repression of IGF-1R, mammalian target of rapamycin (mTOR), signal transducer and activator of transcription 3 (STAT3) and c-Myc mRNA levels. Ectopic expression of miR-486-5p in Huh-7 cells markedly repressed cellular viability, proliferation, migration and clonogenicity in a similar pattern to IGF-1R small interfering RNAs, and were evaluated using 3-(4,5-dimethylthiazol-2-yl)-2,5-diphenyltetrazolium bromide, BrdU incorporation, wound healing and colony forming assays, respectively. Overall, the study findings demonstrated that miR-486-5p acts as a tumor suppressor in HCC through the repression of essential members of the
\end{abstract}

Correspondence to: Professor Ahmed Ihab Abdelaziz, Department of Pharmacology and Toxicology, Faculty of Pharmacy and Biotechnology, German University in Cairo, Main Entrance (Gate 1), 5th Compound, Beside Arabella Compound, New Cairo City, Cairo 11835, Egypt

E-mail: ahmed.ihab.abdelaziz@gmail.com

Abbreviations: HCC, hepatocellular carcinoma; IGF-1R, insulin-like growth factor 1 receptor; BrdU, bromodeoxyuridine; STAT3, signal transducer and activator of transcription 3; mTOR, mammalian target of rapamcyin; MTT, 3-(4,5-dimethylthiazol-2-yl)-2,5-diphenyltetrazolium bromide

Key words: microRNA-486-5p, HCC, IGF-1R, mTOR, STAT3, c-Myc
IGF-axis, including IGF-1R and its downstream mediators mTOR, STAT3 and c-Myc.

\section{Introduction}

The insulin-like growth factor (IGF) axis has been reported by several studies to be among the most deregulated signaling pathways in several types of neoplasm, including hepatocellular carcinoma (HCC) $(1,2)$. The IGF axis and principally the gate-keeper of this pathway, IGF-1 receptor (IGF-1R), has recently been identified as a potential target for the treatment of HCC. To achieve this, several IGF-1R inhibitors were developed, including small molecules, monoclonal antibodies, antisense oligonucleotides and small interfering (si)RNAs (3-7). However, an unpredictable mechanism of resistance to IGF-1R inhibitors was observed (8). Compensatory activation of associated downstream signaling pathways, including the phosphoinositide 3-kinase (PI3K)/AKT/mammalian target of rapamycin (mTOR), Janus kinase (JAK)/signal transducer and activator of transcription (STAT) pathway and RAS/RAF/mitogen-activated protein kinase (MAPK) signaling cascades (Fig. 1), emerged as a critical mechanism of drug resistance in HCC cells (9-11). Hence, targeting a single point in this pivotal signaling pathway was found to induce compensatory up- and/or downstream activation, resulting in drug resistance $(12,13)$. However, a vertical and/or horizontal blockage of this axis may solve this problem.

MicroRNAs (miRNAs/miRs) are small non-coding RNAs ( $\sim 22$ nucleotides long) that act post-transcriptionally to regulate gene expression (14). The idea of using such epigenetic modulators as therapeutic tools is highly compelling due to the fact that they can affect hundreds of targets rather than a single one, a trait that gives them the power to shut down an entire deregulated pathway (15). In addition, they have the ability to tune the expression level of their targets instead of blunting it, which is basically less damaging to healthy cells (16). In HCC, the deregulated miRNAs and their role in HCC development have become a focus of interest, and a set of miRNAs have been implicated in HCC carcinogenesis $(17,18)$. Currently, an miRNA drug, MRX34, is undergoing a phase 1 


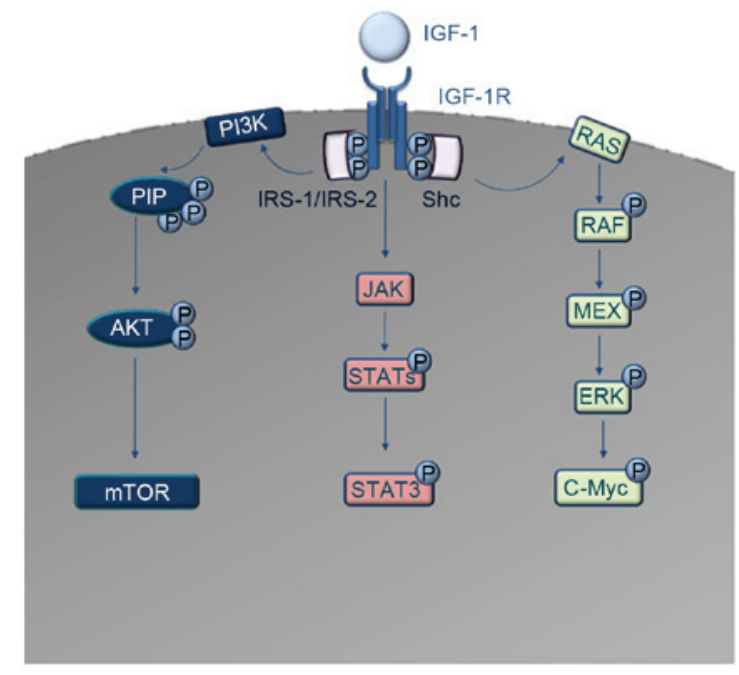

Figure 1. Schematic diagram of the IGF-1R downstream signaling cascades. IGF-1 acts as a ligand to IGF-1R. Autophosphorylation and recruitment of the adaptor proteins IRS-1, IRS-2 and Shc occurs. The interaction of IRS-1 and IRS-2 with IGF-1R induces the activation of PI3K. PI3K converts PIP2 to PIP3, which codes for the activation of AKT and consequently the dis-inhibition of mTOR oncoprotein. In parallel, Shc activation induces the activation of the RAS/RAF/MAPK pathway, which results in activation and phosphorylation of c-Myc transcription factor. Another signaling cascade downstream of IGF-1R is the JAK/STAT pathway, where direct activation of Jak kinases occurs, leading to the activation and phosphorylation of several STAT molecules. The most important of these, STAT3, acts as a transcription factor for numerous oncogenes. IGF-1, insulin-like growth factor 1; IGF-1R, IGF-1 receptor; IRS, insulin receptor substrate; PI3K, phosphatidylinositol 3-kinase; PIP2, phosphatidylinositol 4,5-bisphosphate; PIP3, phosphatidylinositol 3,4,5-trisphosphate; mTOR, mammalian target of rapamycin; MAPK, mitogen-activate protein kinase; JAK, Janus kinase; STAT, signal transducer and activator of transcription.

clinical trial for patients with advanced HCC. This drug is based around miRNA-34a, which is one of the most prominent tumor suppressor miRNAs in HCC (19). The miRNA of other potential tumor suppressors has been found to target several components of the IGF-signaling pathway; for example, miR-615-5p, which was previously reported by our group to directly target IGF-2 (20). Focusing on the gatekeeper of the IGF-axis, IGF-1R, several miRNAs, including miR-145 and miR-99a, have been found to act as tumor suppressors in HCC through direct targeting of IGF-1R $(21,22)$. Notably, it was recently reported that miR-486-5p directly targets IGF-1R in lung cancer (23). However, this has not previously been investigated in HCC. Therefore, the main aim of the present study was to investigate the impact of miR-486-5p on IGF-1R and its downstream signaling mediators, mTOR, STAT3 and c-Myc, in an approach that aids in our understanding of the molecular mechanism of miR-486-5p in HCC.

\section{Materials and methods}

Patients and tissue samples. The present study included 20 hepatitis $\mathrm{C}$ virus (HCV)-induced HCC patients who underwent liver transplant surgery in the Kasr El Einy Hospital, Cairo University (Cairo, Egypt). Due to the scarcity of healthy liver donors, only 10 liver biopsies were obtained from 10 healthy donors during liver transplantation operation. All HCC patients were HCV-positive, with no
Table I. Characteristic features of HCV-induced HCC patients $(n=20)$ and healthy controls $(n=10)$.

\begin{tabular}{|c|c|}
\hline Characteristic & Value \\
\hline \multicolumn{2}{|l|}{ HCC patients } \\
\hline Age (range), years ${ }^{\mathrm{a}}$ & $48.8 \pm 7.8(40.0-63.0)$ \\
\hline Males/females, n & $19 / 1$ \\
\hline Alcohol abuse & None \\
\hline $\mathrm{AST}, \mathrm{U} / \mathrm{l}^{\mathrm{a}}$ & $100.5 \pm 65.8$ \\
\hline $\mathrm{ALT}, \mathrm{U} / \mathrm{1}^{\mathrm{a}}$ & $85.6 \pm 95.6$ \\
\hline $\mathrm{ALP}, \mathrm{U} / \mathrm{l}^{\mathrm{a}}$ & $110.2 \pm 60.7$ \\
\hline Serum albumin, $\mathrm{g} / \mathrm{dl}^{\mathrm{a}}$ & $4.6 \pm 1.5$ \\
\hline Serum AFP, ng/ml ${ }^{\mathrm{a}}$ & $155.7 \pm 22.3$ \\
\hline $\mathrm{HCV} \mathrm{Ab,} \mathrm{\%} \mathrm{(n)}$ & $100.0(20)$ \\
\hline HBV Ab, \% (n) & $15.0(3)$ \\
\hline \multicolumn{2}{|l|}{ Healthy controls (liver donors) } \\
\hline Mean \pm SD age (range), years & $32.1 \pm 7.1(21.0-42.0)$ \\
\hline Males/females, n & $7 / 3$ \\
\hline Alcohol abuse & None \\
\hline $\mathrm{HCV} \mathrm{Ab,} \mathrm{\%} \mathrm{(n)}$ & $0.0(0)$ \\
\hline HBV Ab, \% (n) & $0.0(0)$ \\
\hline
\end{tabular}

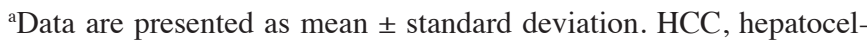
lular carcinoma; $\mathrm{HCV}$, hepatitis $\mathrm{C}$ virus; $\mathrm{HBV}$, hepatitis $\mathrm{B}$ virus; $\mathrm{SD}$, standard deviation; Ab, antibody; AST, aspartate aminotransferase; ALT, alanine aminotransferase; ALP, alkaline phosphatase; AFP, $\alpha$-fetoprotein.

metastases or extrahepatic manifestations, and no invasion of the vascular system. The healthy donors did not suffer from diabetes or hypertension, and were negative for the hepatitis B virus (HBV) and HCV, as shown in Table I. In total, $70 \%$ of the patients presented with $>1$ focal lesion, as determined by the pathology report, and were subjected to clinical assessment according to the Milan criteria (24), as shown in Table II. All patients provided written informed consent, and the study was approved by the Ethical Review Committee of Cairo University. The study complies with the principles set forth in the Declaration of Helsinki and the International Ethical Guidelines For Biomedical Research Involving Human Subjects issued by the Council For International Organizations Of Medical Sciences, and as previously described $(20,25)$.

Cell culture and transfection of oligonucleotides. Huh-7 cells (kindly provided by the Institute of Pathology, Heidelberg University, Heidelberg, Germany) were maintained in Dulbecco's modified Eagle's medium (DMEM; Lonza, Basel, Switzerland), supplemented with $4.5 \mathrm{~g} / 1$ glucose, $4 \mathrm{mmol} / 1$ L-glutamine, $10 \%$ fetal bovine serum (Lonza) and Mycozap (1:500; Lonza) (full DMEM) at $37^{\circ} \mathrm{C}$, in a $5 \% \mathrm{CO}_{2}$ atmosphere. The Huh-7 cells were transfected with miR-486-5p mimics and IGF-1R siRNAs as positive controls in this study (Qiagen GmbH, Hilden, Germany). All transfection experiments were performed in triplicates using HiPerfect Transfection Reagent (Qiagen $\mathrm{GmbH}$ ) according to the 
Table II. Number/sizes of lesions according to the Milan criteria (24).

\begin{tabular}{lcc}
\hline Patient no. & Number of lesions & Size of lesions, cm \\
\hline 1 & 3 focal lesions & $1.5,1$ and 1 \\
2 & Unifocal & 2.5 \\
3 & 3 focal lesions & $2,2.5,3$ \\
4 & 3 focal lesions & $2,2,3.5$ \\
5 & Unifocal & $1.5 \times 2$ \\
6 & 3 focal lesions & $3 \times 4,1$ and 1 \\
7 & Unifocal & 4 \\
8 & 3 focal lesions & 4,1 and 1 \\
9 & 3 focal lesions & 1,1 and 1.5 \\
10 & Unifocal & 2.5 \\
11 & 2 focal lesions & 1 and 1.7 \\
12 & 3 focal lesions & 1,1 and 1 \\
13 & Unifocal & 3 \\
14 & 3 focal lesions & $3,1.5$ and 2 \\
15 & 3 focal lesions & 1,1 and 4 \\
16 & 2 focal lesions & 3 and 1.5 \\
17 & 2 focal lesions & 1.5 and 3 \\
18 & 3 focal lesions & $2.5,2.5$ and 1.5 \\
19 & 3 focal lesions & $1.5,1$ and 1 \\
20 & Unifocal & 2 \\
\hline & &
\end{tabular}

manufacturer's instructions, and experiments were repeated three times. Cells that were only exposed to transfection reagent were designated as mock cells, cells transfected with miR-486-5p mimics were designated as miR-486-5p cells and cells transfected with IGF-1R siRNAs were designated as IGF-1R siRNA cells.

Total RNA extraction from liver biopsies and HCC cell lines. mRNAs and miRNAs were extracted from the liver biopsies and the HCC cells. Fresh liver samples (HCC and healthy tissues) were collected during surgery and snap-frozen in liquid nitrogen. The specimens were manually pulverized in liquid nitrogen and $\sim 100 \mathrm{mg}$ of tissue powder was used for large and small RNA extraction using the mirVana miRNA Isolation Kit (Ambion; Thermo Fisher Scientific Inc., Waltham, MA, USA) according to the manufacturer's instructions. The HCC cells were harvested at $48 \mathrm{~h}$ post-transfection according to the HiPerfect Transfection Reagent protocol: $37.5 \mathrm{ng}$ oligonucleotides were used for Huh-7 cell transfection in a 24-well plate. A spectrophotometer was used to quantify the yield of RNA, and RNA integrity was tested by 18 s rRNA band detection using $1 \%$ agarose gel electrophoresis. The ratio of absorbance at 260 and $280 \mathrm{~nm}$ was used to assess the purity and quantity of RNA yield. A ratio of 2.0 is generally accepted as 'pure' for RNA. Thus, RNA samples with absorbance values outside the range of 1.8-2 were excluded from the study, as previously described $(20,25)$.

miRNA and mRNA quantification. The extracted miRNAs were reverse transcribed into single-stranded complementary
DNA (cDNA) using a TaqMan MicroRNA Reverse Transcription (RT) kit (Applied Biosystems; Thermo Fisher Scientific Inc.) and specific primers ((Applied Biosystems; Thermo Fisher Scientific Inc.) for hsa-miR-486-5p and RNU6B. IGF-1R, STAT3, mTOR and c-Myc mRNAs were reverse transcribed into cDNA using the High-capacity cDNA RT kit (Applied Biosystems; Thermo Fisher Scientific Inc.) according to the manufacturer's instructions. The relative expression of miR-486-5p and RNU6B (as a housekeepong gene for normalization), as well as IGF-1R, STAT3, mTOR, c-Myc and $\beta$-2-microglobulin ( $\beta 2 \mathrm{M}$; as a housekeeping gene for normalization) was quantified using TaqMan RT-quantitative polymerase chain reaction (qPCR; Applied Biosystems Assay IDs: 0002470, 001093, Hs00609566_m1, Hs00374280_m1, Hs00234508_m1, Hs00153408_m1 and Hs00984230_m1, respectively) on a StepOne ${ }^{\mathrm{TM}}$ Real Time PCR instrument (Applied Biosystems; Thermo Fisher Scientific Inc.). For every sample, a reaction mix was prepared according to the manufacturer's instructions, and $4 \mu \mathrm{l}$ of the respective cDNA was added. The RT-qPCR run was performed in the standard mode, consisting of two stages: A first 10 -min stage at $95^{\circ} \mathrm{C}$ where the Taq-polymerase enzyme was activated, followed by a second stage of 40 amplification cycles $\left(15 \mathrm{sec}\right.$ at $95^{\circ} \mathrm{C}$ and $60 \mathrm{sec}$ at $\left.60^{\circ} \mathrm{C}\right)$. Relative expression was calculated using the $2^{-\Delta \Delta \mathrm{Cq}}$ method, as previously described $(20,25)$.

All PCR reactions including controls were run in triplicate reactions.

Cellular viability. In order to determine cellular viability, using the 3-(4,5-dimethylthiazol-2-yl)-2,5-diphenyltetrazolium bromide (MTT) assay, 10,000 Huh-7 cells were seeded in $200 \mu \mathrm{l}$ of culture media (full DMEM) per well in a 96-well plate and incubated $24 \mathrm{~h}$ prior to transfection with $12.5 \mathrm{ng}$ miR-486-5p mimics or IGF-1R siRNAs (according to the HiPerfect protocol; Qiagen $\mathrm{GmbH})$. At $48 \mathrm{~h}$ post-transfection, $20 \mu \mathrm{l}$ MTT solution $(5 \mathrm{mg} / \mathrm{ml}$ MTT in phosphate-buffered saline) was added to each well. Subsequent to incubation for $5 \mathrm{~h}$, formazan (MTT metabolic product) was re-suspended in $200 \mu \mathrm{l}$ dimethyl sulfoxide. Colorimetric measurements and absorbance were performed using a Wallac 1420 Victor2 Multilabel Counter (Perkin Elmer Inc., Waltham, MA, USA), as previously described $(20,25)$.

All cell viability experiments were performed in quadrate and repeated 5 times.

Cellular proliferation. In order to determine cellular proliferation, a BrdU incorporation assay was used. The Huh-7 cells were seeded $24 \mathrm{~h}$ prior to transfection into black 96 -well plates and transfected with $12.5 \mathrm{ng}$ oligonucleotides (according to the HiPerfect protocol; Qiagen $\mathrm{GmbH}$ ) with an initial constant cell count of $5 \times 10^{4}$ cells/well. At $48 \mathrm{~h}$ post-oligonucleotide transfection, the cells were labeled with BrdU labeling reagent for $4 \mathrm{~h}$ (with a final concentration of $100 \mu \mathrm{M}$ ) using the Cell Proliferation ELISA kit (Roche Applied Science, Penzberg, Germany). The cells were then fixed using FixDenate for $30 \mathrm{~min}$ and incubated with Anti-BrdU POD (with a final concentration of $10 \mu \mathrm{M})$ for $90 \mathrm{~min}$, as previously described $(20,25)$.

All cellular proliferation experiments were performed in quadrate and repeated 5 times. 
A

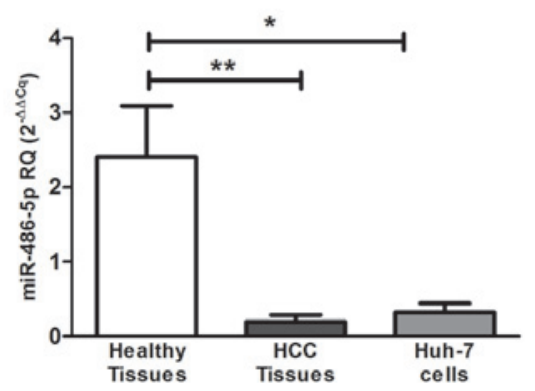

B

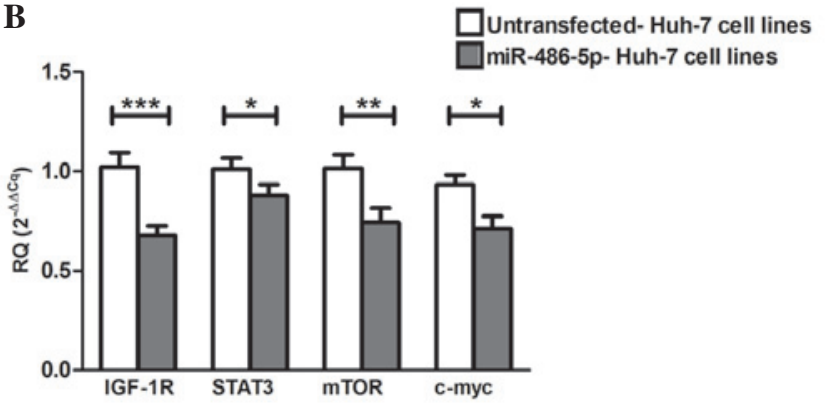

Figure 2. Screening of miR-486-5p in HCC tissues and Huh-7 cells, and the impact of ectopic expression of miR-486-5p on IGF-1R and its downstream mediators in Huh-7 cells. (A) Screening of miR-486-5p in liver tissues showed significant downregulation in the liver tissues obtained from the HCC patients $(\mathrm{P}=0.0022)$ and in the Huh-7 cells $(\mathrm{P}=0.0121)$ when compared with normal liver tissues. (B) Forcing the expression of miR-486-5p in Huh-7 cells resulted in the repression of IGF-1R mRNA expression compared with that of the mock cells $(\mathrm{P}=0.0003)$. Similarly, STAT3, mTOR and c-Myc mRNA levels were also found to be significantly downregulated compared with those of the mock cells $\left(\mathrm{P}=0.0472, \mathrm{P}=0.0086\right.$ and $\mathrm{P}=0.0159$, respectively). ${ }^{*} \mathrm{P}<0.05,{ }^{* *} \mathrm{P}<0.01$ and ${ }^{* * * *} \mathrm{P}<0.001$. HCC, hepatocellular carcinoma; IGF-1, insulin-like growth factor 1; IGF-1R, IGF-1 receptor; mTOR, mammalian target of rapamycin; STAT, signal transducer and activator of transcription; miR, microRNA; RQ, relative quantification.

\section{Growth assays}

Colony-forming assay. Huh-7 cells (1,500 cells/well) were seeded and left to adhere overnight. At $48 \mathrm{~h}$ post-transfection, the cells were detached and imbedded in soft agarose; the bottom layer was prepared with $0.76 \%$ agarose and the top layer with $0.36 \%$ agarose, in culture media (full DMEM). The cells were incubated at $37^{\circ} \mathrm{C}$ for 2 weeks to allow for colonization. The colonies were then stained with crystal violet dye and their numbers were counted per well. All colony-forming assays were performed in triplicate (3 wells/test) and repeated 5 times, as described previously $(20,25)$.

Cell scratch wound healing assay. Huh-7 cells were left in 24-well plates until they had reached $85-95 \%$ confluence. At $48 \mathrm{~h}$ post-transfection, 3 scratches/well were made in each plate with a $20-\mu 1$ pipette tip. Serum-free medium was used to wash off detached cells. Culture medium (full DMEM) was then added, and the culture plates were incubated at $37^{\circ} \mathrm{C}$, in a $5 \% \mathrm{CO}_{2}$ atmosphere. At $24 \mathrm{~h}$ post-scratching, migration was documented, and the quantification of wound closure was performed using Zen2012 software by measuring the surface area of the scratch. All scratch assays were performed in triplicate (3 wells/test, representing 9 scratches/test) and repeated 3 times, as described previously $(20,25)$.

Statistical analysis. A Mann-Whitney U test was performed to compare gene expression between two independent groups. $\mathrm{P}<0.05$ was considered to indicate a statistically significant difference. All the data were statistically analyzed using GraphPad Prism 5.0 (Graphpad Software Inc., La Jolla, CA, USA).

\section{Results}

Screening of miR-486-5p in healthy liver tissues, $H C V$-induced HCC liver tissues and Huh-7 cell lines. miR-486-5p exhibited significant downregulation in the $\mathrm{HCV}$-induced $\mathrm{HCC}$ tissues $(\mathrm{P}=0.0022)$ and Huh-7 cell lines $(\mathrm{P}=0.0121)$ when compared with the liver tissues obtained from healthy donors (Fig. 2A).

Impact of miR-486-5p on its target IGF-1R and its downstream mediators in Huh-7 cells. The ectopic expression of
miR-486-5p in the Huh-7 cells resulted in significant downregulation of the mRNA levels of IGF-1R and its downstream mediators mTOR, STAT3 and c-Myc compared with those of the mock cells $(\mathrm{P}=0.0003, \mathrm{P}=0.0472, \mathrm{P}=0.0086$ and $\mathrm{P}=0.0159$, respectively) (Fig. 2B).

Functional analysis of miR-486-5p in Huh-7 cell lines. After proving the impact of miR-486-5p on IGF-1R and its downstream signaling cascades, given that miR-486-5p has been rarely investigated in HCC and has never been functionally analyzed in Huh-7 cell lines, several functional analysis experiments were performed to evaluate the overall effect of miR-486-5p on various characteristic properties of tumor cells.

Impact of miR-486-5p on cellular viability and proliferation. An MTT assay was used for investigating cell viability and growth. Transfection with miR-486-5p mimics led to a significant decline in cellular viability compared with that in the mock cells $(\mathrm{P}=0.0301)$, in the same manner as the positive control IGF-1R siRNAs used in the study (Fig. 3A).

A BrdU incorporation assay was used for investigating cell proliferation and growth. Forcing the expression of miR-486-5p significantly reduced cellular proliferation compared with the mock Huh-7 cells $(\mathrm{P}=0.0325)$, in the same manner as the IGF-1R siRNAs (Fig. 3B).

Impact of miR-486-5p on cellular migration in Huh-7 cells. Images for the two-dimensional scratch-migration assay were documented at 10-fold magnification. Cellular migration was calculated as the percentage of wound closure. Representative pictures of the scratches are shown in Fig. 4A. The transfection of the Huh-7 cells with miR-486-5p mimics led to a marked reduction in tumor cell migration compared with that in the mock cells $(\mathrm{P}=0.0286)$, which was comparable to the effect of IGF-1R siRNAs (Fig. 4B).

Impact of miR-486-5p on cellular anchorage-independent growth in Huh-7 cells. miR-486-5p intended overexpression resulted in a considerable inhibition of colony formation $(26.7 \pm 2.4)$ in the Huh-7 cells compared with the mock cells $(114.3 \pm 7.9)$, which was comparable to the positive control knockdown cells that were transfected with IGF-1R siRNAs (22.4 \pm 2.8$)$ (Fig. 5). 
A

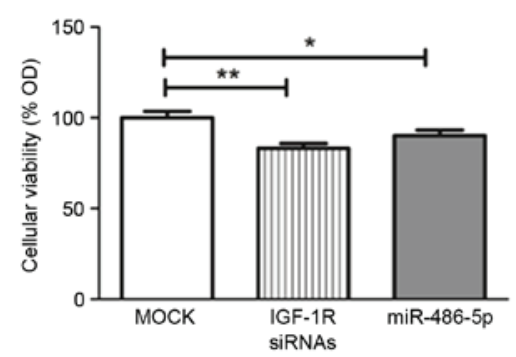

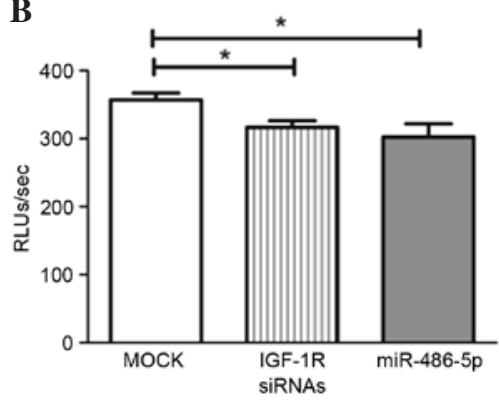

Figure 3. Impact of miR-486-5p on cellular viability and proliferation. (A) 3-(4,5-dimethylthiazol-2-yl)-2,5-diphenyltetrazolium bromide assay: Similar to positive control knockdown cells transfected with IGF-1R siRNAs, miR-486-5p mimic Huh-7 cells showed a significant decrease in the cellular viability compared with the mock cells ( $\mathrm{P}=0.0301)$. (B) BrdU assay: Similar to IGF-1R siRNAs, miR-486-5p-transfected cells showed a significant reduction in cellular proliferation compared with the mock cells $(\mathrm{P}=0.0325)$. ${ }^{*} \mathrm{P}<0.05$ and ${ }^{* *} \mathrm{P}<0.01$. OD, optical density; siRNA, small interfering RNA; IGF-1R, insulin-like growth factor 1 receptor; miR, microRNA.
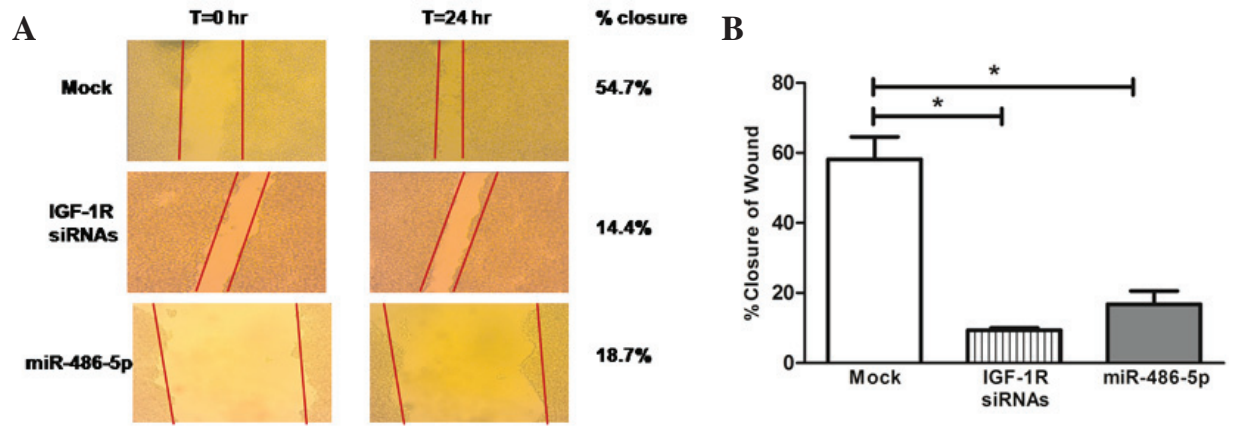

Figure 4. Impact of miR-486-5p on cellular migration. (A) Representative images taken of scratches at the 0 and $24 \mathrm{~h}$ time points. Areas of scratches were measured using Zen2012 software. Cellular migration was calculated as the percentage of wound closure. (B) Similar to the positive control knockdown cells transfected with IGF-1R siRNAs, miR-486-5p mimic cells showed a significant reduction in tumor cell migration compared with the mock cells ( $\mathrm{P}=0.0286)$. ${ }^{*} \mathrm{P}<0.05$. siRNA, small interfering RNA; IGF-1R, insulin-like growth factor 1 receptor; miR, microRNA.

A
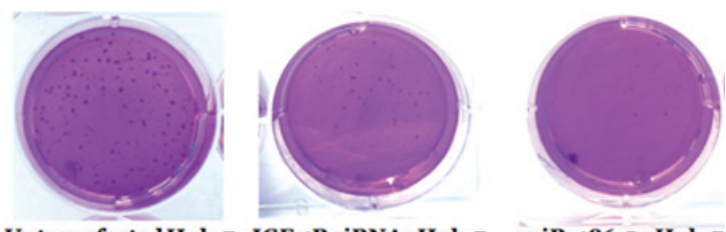

Untransfected Huh-7 IGF-1R siRNAs Huh-7 miR-486-5p Huh-7

$\mathbf{B}$

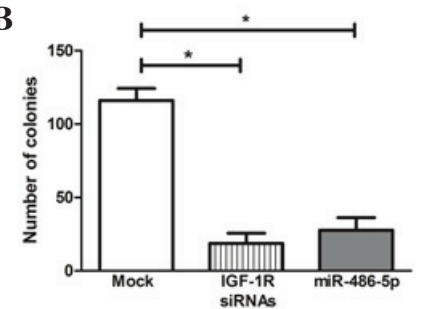

Figure 5. Impact of miR-486-5p on anchorage-independent growth. (A) Representative images of plates showing colonies stained with crystal violet solution at 2 weeks post-incubation. (B) IGF-1R siRNAs and miR-486-5p mimics with noticeably decreased clonogenicity compared with the mock cells. ${ }^{*} \mathrm{P}<0.05$. siRNA, small interfering RNA; IGF-1R, insulin-like growth factor 1 receptor; miR, microRNA.

\section{Discussion}

Deregulation of the IGF-axis is renowned to contribute to each stage of HCC progression and treatment resistance (1,26-28). On the other hand, studies have identified few potential targets for miR-486-5p, including the antiapoptotic factor olfactomedin-4 (29), Rho GTPase-activating protein 5 (30), the tumor suppressor phosphatase and tensin homolog (31), the proto-oncogene Pim-1 kinase (32) and the chief gatekeeper of the IGF-axis IGF-1R, which was also reported to be a validated target for miR-486-5p in lung cancer (23) thus rendering it as a potential candidate for investigation in HCC.

Studies investigating miR-486-5p in HCC are scarce, and its expression profile has not previously been investigated in $\mathrm{HCV}$-induced HCC liver tissues. Therefore, the present study aimed to screen for miR-486-5p in HCV-induced HCC liver tissues compared with healthy liver tissues. Significant downregulation of miR-486-5p was found in the HCV-induced HCC tissues, as well as in Huh-7 cells (Fig. 2). This corroborates a recent study performed on Chinese patients in which miR-486-5p was also downregulated in HBV-induced HCC tissues (33).

It is important to note that miR-486-5p has also been found to be downregulated in numerous other cancer types, including pancreatic cancer (34), gastric cancer (29), osteosarcoma (35), and lung cancer (23), however, the mechanism of miR-486-5p downregulation in those types of cancer, including $\mathrm{HCC}$, is largely unknown. According to previous studies, miR-486-5p downregulation in HCC tissues could be highly accredited to its chromosomal location (8p11.21), which is one of the most typically occurring genomic deletion regions, containing potential tumor suppressor genes (29). Epigenetic silencing 
through DNA methylation and/or histone deacetylation could also be one of the reasons for miR-486-5p downregulation, particularly in $\mathrm{HCV}$-induced $\mathrm{HCC}$ tissues, as $\mathrm{HCV}$ core protein was recently reported to directly induce DNA methylation in HCC tissues (36,37). However, further studies are required to investigate the exact mechanisms underlying miR-486-5p suppression in HCC.

To elucidate the molecular mechanism of miR-486-5p in HCC, the IGF-axis was the main concern of the present study. miR-486-5p was found to negatively regulate its validated target IGF-1R in Huh-7 cells. Nevertheless, miR-486-5p was able to block the IGF-signaling pathways downstream of IGF-1R, namely the PI3K/AKT/mTOR, JAK/STAT and RAS/RAF/MAPK pathways, by the downregulation of mTOR, STAT3 and c-Myc mRNA levels, respectively (Fig. 2). This could be a direct or indirect effect of miR-486-5p on the downstream mediators, as bioinformatically, miR-486-5p was predicted to target the 3'-UTR of STAT3. By contrast, miR-486-5p was recently found to target an upstream regulator of PI3K/AKT/mTOR known as p85 $\alpha$, thus inhibiting the activation of the PI3K/AKT/mTOR pathway and its interlocked RAS/RAF/MAPK signaling cascade, and indirectly acting as a repressor for mTOR and c-Myc transcription $(33,38)$. It is important to note that due to the limited efficacy of IGF-1R inhibitors as a single therapy in HCC and the compensatory activation of downstream signaling pathways resulting in drug resistance (9-13), a combination of agents targeting multiple molecules in IGF-axis, known as vertical blockade, were previously evaluated in several preclinical studies, and synergistic anti-cancer efficacy was demonstrated $(39,40)$. However, the current study nominates miR-486-5p as a single endogenous biological molecule that could vertically and horizontally block the IGF-signaling pathway, as miR-486-5p was not only able to repress the downstream signaling cascades of IGF-1R, but it could also repress the mRNA level of its other validated target IGF-1, the main ligand of the IGF-axis (23) in Huh-7 cells (Youness et al, unpublished data). This feature ranks miR-486-5p as a possible therapeutic target for HCC, with an expected synergistic anti-tumor effect and reduced resistance compared with any other IGF-1R inhibitors. Further investigations are required to experimentally validate the superiority of miR-486-5p over other IGF-1R inhibitors in the treatment of HCC.

Due to the fact that miR-486-5p was found to have a dual action and can function as a cancer-specific tumor suppressor, as in gastric cancer (29) and non-small cell lung cancer $(23,30)$, or as an aggressive oncomiR as in case of colorectal cancer (41) and glioblastoma (42), it was tempting to mechanistically investigate the role for miR-486-5p as either a tumor suppressor miRNA or an oncomiR in HCC. In the current study, miR-486-5p was shown to act as a tumor suppressor miRNA in HCC as it markedly reduced the Huh-7 cell viability, proliferation, migration and clonogenicity in a similar pattern to that exhibited by IGF-1R siRNAs (Figs. 3-5). These results are in line with those of a recent study performed on QGY-7701 and QGY-7703 HCC cell lines, which reported that miR-486-5p also repressed the migration and induced apoptosis of those types of cells (33).

In conclusion, the potential role of miR-486-5p in vertically and horizontally blocking the IGF-axis, represented by repressing the expression levels of IGF-1R and its downstream mediators mTOR, STAT3 and c-Myc in Huh-7 cells, was investigated in this study. Mechanistically, miR-486-5p was found to act as a potential tumor suppressor miRNA in HCC. Further studies are required to determine if miR-486-5p could be used as a potential therapeutic target for the treatment of HCC.

\section{References}

1. Pollak M: The insulin and insulin-like growth factor receptor family in neoplasia: An update. Nat Rev Cancer 12: 159-169, 2012.

2. Cornellà $\mathrm{H}$, Alsinet $\mathrm{C}$ and Villanueva A: Molecular pathogenesis of hepatocellular carcinoma. Alcohol Clin Exp Res 35: 821-825, 2011.

3. Cervello M, McCubrey JA, Cusimano A, Lampiasi N, Azzolina A and Montalto G: Targeted therapy for hepatocellular carcinoma: Novel agents on the horizon. Oncotarget 3: 236-260, 2012.

4. Chang AY and Wang M: In-vitro growth inhibition of chemotherapy and molecular targeted agents in hepatocellular carcinoma. Anticancer Drugs 24: 251-259, 2013.

5. Cohen BD, Baker DA, Soderstrom C, Tkalcevic G, Rossi AM, Miller PE, Tengowski MW, Wang F, Gualberto A, Beebe JS and Moyer JD: Combination therapy enhances the inhibition of tumor growth with the fully human anti-type 1 insulin-like growth factor receptor monoclonal antibody CP-751,871. Clin Cancer Res 11: 2063-2073, 2005.

6. Lin RX, Wang ZY, Zhang N, Tuo CW, Liang QD, Sun YN and Wang SQ: Inhibition of hepatocellular carcinoma growth by antisense oligonucleotides to type I insulin-like growth factor receptor in vitro and in an orthotopic model. Hepatol Res 37: 366-375, 2007.

7. Rodon J, DeSantos V, Ferry RJ Jr and Kurzrock R: Early drug development of inhibitors of the insulin-like growth factor-I receptor pathway: Lessons from the first clinical trials. Mol Cancer Ther 7: 2575-2588, 2008.

8. Chen KF, Yeh PY, Yeh KH, Lu YS, Huang SY and Cheng AL: Down-regulation of phospho-Akt is a major molecular determinant of bortezomib-induced apoptosis in hepatocellular carcinoma cells. Cancer Res 68: 6698-6707, 2008.

9. van Malenstein H, Dekervel J, Verslype C, Van Cutsem E, Windmolders P, Nevens F and van Pelt J: Long-term exposure to sorafenib of liver cancer cells induces resistance with epithelial-to-mesenchymal transition, increased invasion and risk of rebound growth. Cancer Lett 329: 74-83, 2013.

10. Tai WT, Cheng AL, Shiau CW, Liu CY, Ko CH, Lin MW, Chen PJ and Chen KF: Dovitinib induces apoptosis and overcomes sorafenib resistance in hepatocellular carcinoma through SHP-1-mediated inhibition of STAT3. Mol Cancer Ther 11: 452-463, 2012.

11. Gedaly R, Angulo P, Hundley J, Daily MF, Chen C, Koch A and Evers BM: PI-103 and sorafenib inhibit hepatocellular carcinoma cell proliferation by blocking Ras/Raf/MAPK and PI3K/AKT/mTOR pathways. Anticancer Res 30: 4951-4958, 2010.

12. O'Reilly KE, Rojo F, She QB, Solit D, Mills GB, Smith D, Lane H, Hofmann F, Hicklin DJ, Ludwig DL, et al: mTOR inhibition induces upstream receptor tyrosine kinase signaling and activates Akt. Cancer Res 66: 1500-1548, 2006.

13. Zitzmann K, Rüden Jv, Brand S, Göke B, Lichtl J, Spöttl G and Auernhammer CJ: Compensatory activation of Akt in response to mTOR and Raf inhibitors-a rationale for dual-targeted therapy approaches in neuroendocrine tumor disease. Cancer Lett 295: 100-109, 2010.

14. Friedman RC, Farh KK, Burge CB and Bartel DP: Most mammalian mRNAs are conserved targets of microRNAs. Genome Res 19: 92-105, 2009.

15. Lewis BP, Burge CB and Bartel DP: Conserved seed pairing, often flanked by adenosines, indicates that thousands of human genes are microRNA targets. Cell 120: 15-20, 2005.

16. Pillai RS, Bhattacharyya SN and Filipowicz W: Repression of protein synthesis by miRNAs: How many mechanisms? Trends Cell Biol 17: 118-126, 2007.

17. Lan FF, Wang H, Chen YC, Chan CY, Ng SS, Li K, Xie D, He ML, Lin MC and Kung HF: Hsa-let-7g inhibits proliferation of hepatocellular carcinoma cells by downregulation of c-Myc and upregulation of p16(INK4A). Int J Cancer 128: 319-331, 2011. 
18. Croce CM: Causes and consequences of microRNA dysregulation in cancer. Nat Rev Genet 10: 704-714, 2009.

19. He L, He X, Lim LP, de Stanchina E, Xuan Z, Liang Y, Xue W, Zender L, Magnus J, Ridzon D, et al: A microRNA component of the p53 tumour suppressor network. Nature 447: 1130-1134, 2007.

20. El Tayebi HM, Hosny KA, Esmat G, Breuhahn K and Abdelaziz AI: miR-615-5p is restrictedly expressed in cirrhotic and cancerous liver tissues and its overexpression alleviates the tumorigenic effects in hepatocellular carcinoma. FEBS Lett 586: 3309-3316, 2012.

21. Law PT, Ching AK, Chan AW, Wong QW, Wong CK, To KF and Wong N: MiR-145 modulates multiple components of the insulin-like growth factor pathway in hepatocellular carcinoma. Carcinogenesis 33: 1134-1341, 2012

22. Li D, Liu X, Lin L, Hou J, Li N, Wang C, Wang P, Zhang Q, Zhang P, Zhou W, et al: MicroRNA-99a inhibits hepatocellular carcinoma growth and correlates with prognosis of patients with hepatocellular carcinoma. J Biol Chem 286: 36677-36685, 2011.

23. Peng Y, Dai Y, Hitchcock C, Yang X, Kassis ES, Liu L, Luo Z, Sun HL, Cui R, Wei H, et al: Insulin growth factor signaling is regulated by microRNA-486, an underexpressed microRNA in lung cancer. Proc Natl Acad Sci USA 110: 15043-15048, 2013.

24. Mazzaferro V, Regalia E, Doci R, Andreola S, Pulvirenti A, Bozzetti F, Montalto F, Ammatuna M, Morabito A and Gennari L: Liver transplantation for the treatment of small hepatocellular carcinomas in patients with cirrhosis. N Engl J Med 334: 693-699, 1996

25. El Tayebi HM, Omar K, Hegy S, El Maghrabi M, El Brolosy M, Hosny KA, Esmat G and Abdelaziz AI: Repression of miR-17-5p with elevated expression of E2F-1 and c-MYC in non-metastatic hepatocellular carcinoma and enhancement of cell growth upon reversing this expression pattern. Biochem Biophys Res Commun 434: 421-427, 2013.

26. De Meyts P: Insulin and its receptor: Structure, function and evolution. Bioessays 26: 1351-1362, 2004.

27. Durzyńska J: IGF axis and other factors in HPV-related and HPV-unrelated carcinogenesis (review). Oncol Rep 32: 2295-2306, 2014.

28. Shaw RJ, Lamia KA, Vasquez D, Koo SH, Bardeesy N, Depinho RA, Montminy M and Cantley LC: The kinase LKB1 mediates glucose homeostasis in liver and therapeutic effects of metformin. Science 310: 1642-1646, 2005.

29. Oh HK, Tan AL, Das K, Ooi CH, Deng NT, Tan IB, Beillard E, Lee J, Ramnarayanan K, Rha SY, et al: Genomic loss of miR-486 regulates tumor progression and the OLFM4 antiapoptotic factor in gastric cancer. Clin Cancer Res 17: 2657-2667, 2011.

30. Wang J, Tian X, Han R, Zhang X, Wang X, Shen H, Xue L, Liu Y, Yan X, Shen J, et al: Downregulation of miR-486-5p contributes to tumor progression and metastasis by targeting protumorigenic ARHGAP5 in lung cancer. Oncogene 33: 1181-1189, 2014.

31. Small EM, O'Rourke JR, Moresi V, Sutherland LB, McAnally J, Gerard RD, Richardson JA and Olson EN: Regulation of PI3-kinase/Akt signaling by muscle-enriched microRNA-486. Proc Natl Acad Sci USA 107: 4218-4223, 2010.
32. Pang W, Tian X, Bai F, Han R, Wang J, Shen H, Zhang X, Liu Y, Yan X, Jiang F and Xing L: Pim-1 kinase is a target of miR-486-5p and eukaryotic translation initiation factor 4E, and plays a critical role in lung cancer. Mol Cancer 13: 240, 2014.

33. Huang XP, Hou J, Shen XY, Huang CY, Zhang XH, Xie YA and Luo XL: MicroRNA-486-5p, which is downregulated in hepatocellular carcinoma, suppresses tumor growth by targeting PIK3R1. FEBS J 282: 579-594, 2015.

34. Ali S, Saleh H, Sethi S, Sarkar FH and Philip PA: MicroRNA profiling of diagnostic needle aspirates from patients with pancreatic cancer. Br J Cancer 107: 1354-1360, 2012.

35. Namløs HM, Meza-Zepeda LA, Barøy T, Østensen IH, Kresse SH, Kuijjer ML, Serra M, Bürger H, Cleton-Jansen AM and Myklebost O: Modulation of the osteosarcoma expression phenotype by microRNAs. PLoS One 7: e48086, 2012.

36. Lim JS, Park SH and Jang KL: Hepatitis C virus Core protein overcomes stress-induced premature senescence by down-regulating p16 expression via DNA methylation. Cancer Lett 321: 154-161, 2012.

37. Dong Y and Wang A: Aberrant DNA methylation in hepatocellular carcinoma tumor suppression (Review). Oncol Lett 8: 963-968, 2014.

38. Pourdehnad M, Truitt ML, Siddiqi IN, Ducker GS, Shokat KM and Ruggero D: Myc and mTOR converge on a common node in protein synthesis control that confers synthetic lethality in Myc-driven cancers. Proc Natl Acad Sci USA 110: 11988-11993, 2013.

39. Mazzoletti M, Bortolin F, Brunelli L, Pastorelli R, Di Giandomenico S, Erba E, Ubezio P and Broggini M: Combination of PI3K/mTOR inhibitors: Antitumor activity and molecular correlates. Cancer Res 71: 4573-4584, 2011

40. Floc'h N, Kinkade CW, Kobayashi T, Aytes A, Lefebvre C, Mitrofanova A, Cardiff RD, Califano A, Shen MM and Abate-Shen C: Dual targeting of the Akt/mTOR signaling pathway inhibits castration-resistant prostate cancer in a genetically engineered mouse model. Cancer Res 72: 4483-4493, 2012.

41. Ragusa M, Majorana A, Statello L, Maugeri M, Salito L, Barbagallo D, Guglielmino MR, Duro LR, Angelica R, Caltabiano R, et al: Specific alterations of microRNA transcriptome and global network structure in colorectal carcinoma after cetuximab treatment. Mol Cancer Ther 9: 3396-3409, 2010.

42. Song L, Lin C, Gong H, Wang C, Liu L, Wu J, Tao S, Hu B, Cheng SY, Li M and Li J: miR-486 sustains NF-kB activity by disrupting multiple NF-kB-negative feedback loops. Cell Res 23: 274-289, 2013 